\title{
OR-7
}

\section{EXPERIMENTAL STUDIES OF THE PROCESS OF COOLANT EVAPORATION}

\author{
A.P. Khomyakov, V. S. Kryukova, V. N. Gushshamova, S. S. Petsura, I. S. Kovalev, \\ S. V. Mordanov, T. V. Khomyakova \\ Ural Federal University of the first President of Russia B. N. Yeltsin, 19 Mira St., Yekaterinburg, \\ 620002, Russia. \\ E-mail: 89126634949@yandex.ru
}

\begin{abstract}
Cooling lubricants based on triethanolamine (CL) are widely used in metal processing because of need for cooling in the processing area of the product, reducing tool wear, and ensuring quality of the processed surface $[1,2,3,4]$. It is advisable to pre-concentrate the coolant for disposal.

The experiments were carried out on a pilot evaporation installation, shown in figure 1. Experimental studies of CL evaporation were carried out at the mass fraction of dry substances in the solution from 4.1 to $76.7 \%$.
\end{abstract}

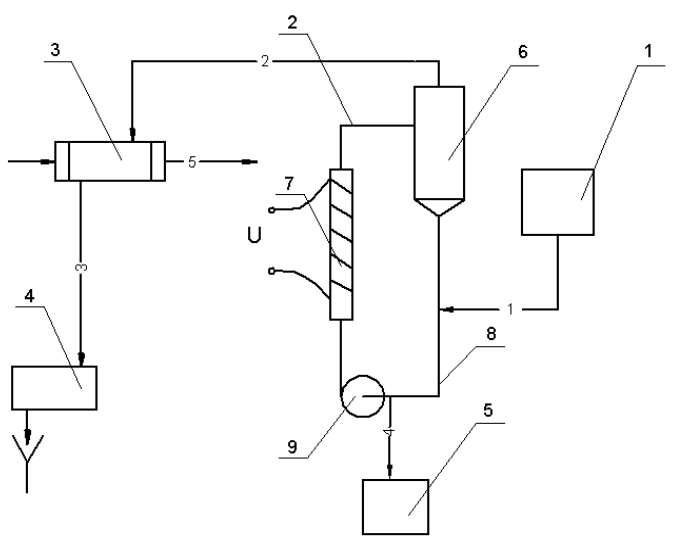

1. Initial solution tank

2. Evaporation unit

3. Condenser

4. Condensate tank

5. $\quad$ Finished product tank
6. Separato

7. Heating chamber

8. Circulation pipe

$-1-$ Initial solution; - $2-$ Secondary steam; - $3-$ Condensate;

$-4-$ Finished product; $\_5-$ Cooling water

Figure 1. Scheme of experimental evaporation installation

The results of experimental studies have shown that it is possible to thicken the cooling lubricants in evaporators.

In the study, we obtained the following dependence: density change of CL temperature at various mass fraction of dry substances in the solution; change the CL boiling point from the mass fraction of dry substances in the solution; change the CL dynamic viscosity from the mass fraction of dry substances in the solution at temperature of $20^{\circ} \mathrm{C}$ and $40^{\circ} \mathrm{C}$.

We obtained the relationships of changes in the CL density as a function of temperature for the mass fraction of dry substances in the solution of $4.1 \%, 16.4 \%, 37.8 \%$ and $76.7 \%$. In addition, we obtained relationship of changes of the CL boiling point from the mass fraction of dry substances in the solution.

\section{References}

1. Priarone P.C. On the concurrent optimization of environmental and economic targets for machining // Journal of Cleaner Production. - vol. 190 - 2018. - P. 630-644

2. Amiril A.S. A review on ionic liquids as sustainable lubricants in manufacturing and engineering: Recent research, performance, and applications // Journal of Cleaner Production. - vol.168 - 2017. - P. 1571-1589

3. Benedicto E. Technical, Economic and Environmental Review of the Lubrication/Cooling Systems Used in Machining Processes // Procedia Engineering. - Vol. 184 - 2017. - P. 99-116

4. Denkena B. Energy Efficient Machining with Optimized Coolant Lubrication Flow Rates // Procedia CIRP. - Vol.24 2014. - P. 25-31 